\title{
Characteristics of Phosphorus Adsorption of Acidic, Calcareous, and Plastic Film House Soils
}

\author{
Myung-Sook Kim*, Seong-Jin Park, Chang-Hoon Lee, Sun-Gang Yun, Byong-Gu Ko, and Jae E. Yang \\ Soil \& Fertilizer Management Division, National Institute of Agricultural Science, Wanju 55365, Rep. of Korea
}

(Received: October 24 2016, Revised: November 18 2016, Accepted: November 21 2016)

Continuous excessive application of phosphorus (P) fertilizer and manure in plastic film house soils can lead to an accumulation of $P$ in soils. The understanding of $P$ sorption by soils is important for fertilizer management. In this study, 9 samples were collected for acidic and calcareous soils as non-cultivated soil and plastic film house soils as cultivated soil Phosphorus sorption data of acidic soils fit the Langmuir equations, Freundlich equations in calcareous and plastic film house soils. In calcareous and plastic film house soils, the slope of isotherm adsorption changed abruptly, which could be caused $\mathrm{P}$ precipitation with $\mathrm{CaCO}_{3}$. The calculated Langmuir adsorption maximum ( $\left(S_{\max }\right)$ varied from 217 to $1,250,139$ to 1,429 , and $714 \mathrm{mg} \mathrm{kg}^{-1}$ for acidic soils, calcareous soils, and plastic film house soils with low available phosphate concentration, respectively. From this result, maximum $P$ adsorption by the Langmuir equation could be regarded as threshold of $P$ concentration to induce the phosphate precipitation in soil. Phosphate-sorption values estimated from one-point isotherm for acidic and calcareous soils as non-cultivated soils were comparable with the $\mathbf{S}_{\max }$ values calculated from the Langmuir isotherm.

Key words: Phosphorus, Maximum adsorption capacity, Soil characteristics

Langmuir and Freundlich isothem adsorption parameters of acidic, calcareous, and plastic film house soils.

\begin{tabular}{|c|c|c|c|c|c|}
\hline \multirow{3}{*}{ Soils } & \multirow{3}{*}{ Soil no. } & \multicolumn{2}{|c|}{ Langmuir } & \multicolumn{2}{|c|}{ Freundlich } \\
\hline & & $\mathrm{S}_{\max }$ & $\mathrm{k}$ & $\mathrm{K}_{\mathrm{d}}$ & $\mathrm{n}$ \\
\hline & & $\mathrm{mg} \mathrm{kg}^{-1}$ & $\mathrm{~L} \mathrm{mg}^{-1}$ & $\mathrm{~L} \mathrm{~kg}^{-1}$ & \\
\hline \multicolumn{6}{|c|}{ Non-cultivated soils } \\
\hline \multirow{3}{*}{ Acidic soils } & Soil 1 & 217 & 0.438 & 49 & 0.419 \\
\hline & Soil 2 & 909 & 0.262 & 304 & 0.289 \\
\hline & Soil 3 & 1,250 & 0.123 & 294 & 0.321 \\
\hline \multirow{3}{*}{$\begin{array}{l}\text { calcareous } \\
\text { soils }\end{array}$} & Soil 4 & 139 & 0.159 & 33 & 0.334 \\
\hline & Soil 5 & 769 & 0.048 & 168 & 0.277 \\
\hline & Soil 6 & 1,429 & 0.029 & 318 & 0.239 \\
\hline \multicolumn{6}{|c|}{ Cultivated soils } \\
\hline \multirow{3}{*}{$\begin{array}{l}\text { Plastic film } \\
\text { house soils }\end{array}$} & Soil 7 & 714 & 0.014 & 36 & 0.518 \\
\hline & Soil 8 & - & - & - & - \\
\hline & Soil 9 & - & - & - & - \\
\hline
\end{tabular}

$\mathrm{S}_{\max }$ is $\mathrm{P}$ maximum sorption, $\mathrm{k}$ : a constant to the bonding energy, $\mathrm{K}_{\mathrm{d}}$ and $\mathrm{n}$ are constants for a given adsorbate and adsorbent at a particular temperature. 


\section{Introduction}

최근 우리나라 농경지 중 시설재배지의 유효인산 평균 함 량은 $1,049 \mathrm{mg} \mathrm{kg}^{-1}$ 으로 적정범위 (350 $500 \mathrm{mg} \mathrm{kg}^{-1}$ )보다 2 배 이상 많고, 최대 함량은 $4,238 \mathrm{mg} \mathrm{kg}^{-1}$ 에 달하는 것으로 나 타났다 (RDA, 2013). 이것은 농경지에 투입하는 인산질비료의 영향이 크며, 인산질 비료의 단위 면적당 잠재사용량은 2010 년에 $120 \mathrm{~kg} \mathrm{ha}^{-1}$ (Yun et al., 2013)로 시설재배지의 비료 표 준 사용량인 30 106 kg ha ${ }^{-1}$ (NIAST, 2006) 보다 1.1 4.0배 많이 투입되고 있기 때문이다.

농경지에 인산질 비료를 투입하면 토양표면에 인이 흡착 되기 시작하여 최대 흡착량에 도달하고 그 이후부터 과잉으 로 포화되어 침전 반응이 일어날 수 있다고 하였다 (Zhou and $\mathrm{Li}, 2001)$. 이를 근거로 할 경우 국내 시설재배지 토양은 흡착을 거쳐 침전형태로 존재할 가능성이 높으며 침전형태 는 작물에 대한 인의 유효도를 저하키는 원인이 된다. 따라서 이를 해결하기 위한 기초연구로 토양의 인 흡착 특성과 최대 로 보유할 수 있는 인을 정량하는 것은 매우 중요하다.

토양의 인 흡착 기작은 모델식을 이용하여 설명하였는데, 대 표적인 모델식으로 Langmuir (Langmuir, 1918)와 Freundlich (Sparks, 2003)이 있다. Langmuir 식은 비록 고체의 가스 흡 착을 기술한 실험에서 시작하였을지라도 토양에서 인 흡착 을 설명하는데 많이 사용되고 있다. Langmuir 식은 최대 흡 착량을 구할 수 있고 인 결합세기가 일정하다는 장점이 있으 며, Freundlich식은 넓은 범위의 농도에서의 흡착 현상에 통 용될 수 있는 경험식이라는 특성이 있다. 토양특성별 인 흡착 에 관하여 다양하게 연구되었다. 동남아시아의 일부 산성토 양에서 Freundlich, Langmuir, Tempkin 식을 적용하여 Langmuir식이 더 잘 맞는다고 하였고 (Sanyal et al., 1993), 하와이와 인도의 일부 산성 토양 (Rajan and Fox, 1974), 국
내의 광질 토양과 화산회 토양 (Ryu, 1975)에서 Langmuir식 이 잘 맞는다고 하였다. 스페인 남부지역의 석회암 토양 (Solis and Torrent, 1989), 미국 플로리다지역의 석회암과 염기성 토양 (Zhou and Li, 2001)에 Freundlich 식을 적용하 였으며 토양에 따라 적용되는 모델식이 다르게 나타났다.

토양의 인 흡착은 $\mathrm{pH}$ (Barrow, 1984), 점토 함량 (Fox and Kamprath, 1970; Sanyal et al., 1993)에 영향을 크게 받는 다. 토양의 인 흡착량은 $\mathrm{pH}$ 가 증가할수록 감소하며, 점토함 량이 많아질수록 증가한다고 하였다. 특히, 산성토양의 인 흡착은 점토 중에 추출성 $\mathrm{Fe}$ 과 $\mathrm{Al}$ 산화물과 관계가 크다고 하 였다 (Fox and Kamprath, 1970; Sanyal et al., 1993). 석회 암 토양의 인 흡착에 있어서 Ryan et al. (1985)에 따르면 $\mathrm{CaCO}_{3}$ 보다 $\mathrm{Fe}$ 산화물에 영향을 크게 받는다고 하였으나, Zhou and Li et al., (2001)에 의하면 인의 농도가 높을 경우 $\mathrm{CaCO}_{3}$ 함유한 점토함량에 영향을 크게 받는다고 하였다.

따라서 본 연구의 목적은 토양 특성별로 인의 흡착 기작 및 최대 흡착량을 평가하기 위해 $\mathrm{pH}$, 점토함량이 다른 미경 작지 토양과 유효인산 함량이 높은 시설재배지의 경작지 토 양을 대상으로 분석하였다.

\section{Materials and Methods}

공시 토양 특성 미경작지로 산성 (여주) 및 석회암 (영 월, 단양) 토양을, 경작지로 시설재배 토양 (천안, 평택의 시 설오이 재배지)을 채취하였고, 이화학적 특성은 Table 1과 같 다. 미경작지인 산성토양의 $\mathrm{pH}$ 범위는 4.4 4.5이고, 점토 함량은 $11 \sim 37 \%$ 이었으며, 석회암 토양의 $\mathrm{pH}$ 범위는 8.0 8.2 이고, 점토함량은 $4 \sim 46 \%$ 이었다. 이 토양들의 인 흡착 시 다른 요인의 영향을 최소화하기 위해 전기전도도 (0.22 $0.50 \mathrm{dS} \mathrm{m}^{-1}$ )와 유효인산 함량 (1 22 mg kg${ }^{-1}$ ), 유기물 함량

Table 1. Physico-chemical properties of the experimental soils.

\begin{tabular}{|c|c|c|c|c|c|c|c|c|c|c|c|}
\hline \multirow{2}{*}{ Soil type } & \multirow{2}{*}{$\begin{array}{c}\text { Sample } \\
\text { no. }\end{array}$} & \multirow{2}{*}{$\begin{array}{c}\mathrm{pH} \\
\left(1: 5 \mathrm{H}_{2} \mathrm{O}\right)\end{array}$} & \multirow{2}{*}{$\begin{array}{c}\mathrm{EC} \\
\left(\mathrm{dS} \mathrm{m}^{-1}\right)\end{array}$} & \multirow{2}{*}{$\begin{array}{c}\mathrm{OM} \\
\left(\mathrm{g} \mathrm{kg}^{-1}\right)\end{array}$} & \multirow{2}{*}{$\mathrm{Av}, \mathrm{P}_{2} \mathrm{O}_{5}$} & \multirow{2}{*}{ T-P } & \multicolumn{3}{|c|}{ Exch. cation } & \multirow{2}{*}{ Clay } & \multirow{2}{*}{$\mathrm{CaCO}_{3}$} \\
\hline & & & & & & & $\mathrm{Ca}$ & K & $\mathrm{Mg}$ & & \\
\hline \multirow{2}{*}{\multicolumn{12}{|c|}{$\begin{array}{l}\left(\mathrm{g} \mathrm{kg}^{-1}\right) \quad-----\mathrm{mg} \mathrm{kg}^{-} \\
\text {Non-cultivated soils }\end{array}$}} \\
\hline & & & & & & & & & & & \\
\hline \multirow{3}{*}{ Acidic soils } & Soi 11 & 4.4 & 0.22 & 6 & 8 & 180 & 0.1 & 0.06 & 0.1 & 11 & \\
\hline & Soil 2 & 4.5 & 0.24 & 5 & 1 & 158 & 0.2 & 0.04 & 0.1 & 23 & \\
\hline & Soil 3 & 4.4 & 0.39 & 7 & 1 & 218 & 0.6 & 0.15 & 0.7 & 37 & \\
\hline \multirow{3}{*}{$\begin{array}{l}\text { calcareous } \\
\text { soils }\end{array}$} & Soil 4 & 8.2 & 0.27 & 9 & 4 & 256 & 3.6 & 0.00 & 2.3 & 4 & 10.4 \\
\hline & Soil 5 & 8.1 & 0.26 & 10 & 16 & 200 & 15 & 0.26 & 2.3 & 22 & 1.1 \\
\hline & Soil 6 & 8.0 & 0.50 & 13 & 22 & 187 & 18.4 & 0.32 & 2.0 & 46 & 1.5 \\
\hline \multicolumn{12}{|c|}{ Cultivated soils } \\
\hline \multirow{3}{*}{$\begin{array}{l}\text { Plastic film } \\
\text { house soils }\end{array}$} & Soil 7 & 6.9 & 4.70 & 23 & 582 & 1,592 & 13.7 & 0.48 & 6.8 & & 1.3 \\
\hline & Soil 8 & 6.0 & 6.27 & 67 & 1,218 & 2,628 & 15.1 & 3.14 & 5.7 & & 1.6 \\
\hline & Soil 9 & 7.0 & 9.23 & 49 & 2,148 & 2,914 & 12.4 & 4.35 & 9.5 & & 1.2 \\
\hline
\end{tabular}


$\left(5 \sim 13 \mathrm{~g} \mathrm{~kg}^{-1}\right)$ 이 낮은 토양을 대상으로 선정하였다. 경작지인 시설재배 토양의 $\mathrm{pH}$ 는 6.0 7.0이었고, 유효인산 함량은 다양 한 수준 (582 2,148 $\left.\mathrm{mg} \mathrm{g}^{-1}\right)$ 을 가진 토양을 선정하였으며, 전 기전도도 (4.70 9.23)와 유기물 함량 $\left(23 \sim 67 \mathrm{~g} \mathrm{~kg}^{-1}\right)$ 은 미경 지보다 높은 함량을 나타냈다.

토양 분석 $\mathrm{pH}$ 와 $\mathrm{EC}$ 는 토양과 증류수의 비율을 $1: 5$ 로 추 출하여 $\mathrm{pH}$ 와 $\mathrm{EC}$ meter로 측정하였고, 토양유기물은 Tyurin 법, 유효인산은 Lancaster 법으로 $720 \mathrm{~nm}$ 에서 비색계 (U-3000, Hitachi)로 측정하였다. 치환성 양이온은 $1 \mathrm{M} \mathrm{NH}_{4} \mathrm{OAc}(\mathrm{pH}$ 7.0) 완충용액으로 추출하여 유도결합 플라즈마 발광광도계 (ICP-OES, $\mathrm{GBC}$ )로 분석하였다.

토양의 입경분석은 $30 \% \mathrm{H}_{2} \mathrm{O}_{2}$ 로 유기물을 분해하고, $5 \%$ sodium hexametaphosphate로 분산시켜 pipette법으로 측정 하였다 (NIAST, 2000). 그리고 $\mathrm{CaCO}_{3}$ 함량은 Jung and Kim (2006)이 제안한 calcimeter를 이용한 방법을 사용하였다.

등온 흡착 실험 방법 공시 토양 중 soil 1 soil 7은 인 농도를 $0,0.5,1,5,20,40,60,80,100,200,400,600$, $800,1,000,1,200,2,000 \mathrm{mg} \mathrm{P} \mathrm{L}^{-1}$ 로 하였고, soil 8 9은 인 농도를 $0,0.5,1,20,60,100,200,400,600,800,1,000$, $2,000,3,000,4,000,5,000 \mathrm{mg} \mathrm{P} \mathrm{L}^{-1}$ 로 하였다. 토양 $2 \mathrm{~g}$ 에 인 용액 $20 \mathrm{~mL}$ 를 넣고 end-over-end shaker에 24시간 40 $\mathrm{rpm}$ 으로 진탕하고 원심분리를 한 후, $0.45 \mu \mathrm{m}$ 여과지로 여과 한 액 (Zhou and Li, 2001)을 ICP로 분석하였다. 토양의 인 등 온 흡착 모델은 Langmuir (Langmuir, 1918) 식과 Freundlich (Freundlich, 1926) 식을 사용하였다.

Langmuir 식은 Eq. 1과 같이 나타낼 수 있다.

$$
\frac{C_{e}}{q}=\frac{1}{k S_{\max }}+\frac{C_{e}}{S_{\max }}
$$

여기서, $q$ : 평형 시 단위 토양 무게당 인산의 흡착량 $\left(\mathrm{mg} \mathrm{P} \mathrm{kg}{ }^{-1}\right)$

$C_{e}:$ 용액 중 인산의 평형 농도 $\left(\mathrm{mg} \mathrm{P} \mathrm{L}^{-1}\right)$

$k$ : 각 대상 물질이 기질에 대한 결합의 세기와 관련된 상수 $\left(\mathrm{L} \mathrm{mg}^{-1}\right)$

$S_{\max }$ : 단위 토양 무게 당 인산의 최대 흡착량 (mg P kg ${ }^{-1}$ )

이 때 $\frac{1}{S}$ 은 흡착식에서 직선의 기울기이고, $\frac{1}{k S}$ 은 절편을 나타낸다.

Freundlich 식은 다음과 같다(Eq. 2).

$$
q=K_{d} C_{e}^{1 / n}
$$

여기서, $q$ : 평형 시 단위 토양 무게 당 인산의 흡착량 $\left(\mathrm{mg} \mathrm{P} \mathrm{kg}{ }^{-1}\right)$

$$
\begin{aligned}
& K_{d}: \text { 분배 계수 }\left(\mathrm{mg} \mathrm{P} \mathrm{kg}^{-1}\right) \\
& C_{e}: \text { 용액 중 인산의 평형 농도 }\left(\mathrm{mg} \mathrm{P} \mathrm{L}^{-1}\right) \\
& n: \text { 보정인자 (correction factor) }
\end{aligned}
$$

\section{Results and Discussion}

\section{토양 특성별 인산 흡착 특성 미경작지인 산성토양} (soil 1, 2, 3)의 인 흡착은 Freundlich 식 $\left(\mathrm{R}^{2}=0.780 \sim 0.997\right)$ 과 Langmuir 식 $\left(\mathrm{R}^{2}=0.967 \sim 0.997\right)$ 을 모두 따랐고, 결정계 수 $\left(\mathrm{R}^{2}\right)$ 의 값으로 보았을 때 Langmuir 식이 Freundlich 식보 다 인 흡착기작을 더 잘 설명하였다 (Table 2). 석회암 토양 (Soil 4, 5, 6)의 경우 인 흡착에 있어서 Freundlich식 $\left(\mathrm{R}^{2}=\right.$ $0.989 \sim 0.995)$ 과 Langmuir식 $\left(\mathrm{R}^{2}=0.982 \sim 0.984\right)$ 을 모두 따랐지만, Freundlich 식으로 더 잘 설명되었다. 경작지인 시 설재배지 토양 (soil 12, 13, 14)은 석회암 토양과 유사하게 Freundlich식 $\left(\mathrm{R}^{2}=0.869 \sim 0.979\right)$ 으로 잘 설명되었다. Rajan and Fox (1974)에 따르면, 산성 토양에 인 흡착은 Langmuir식이 잘 맞는다고 하였고, Zhou and Li (2001)은 석회암 토양은 Freundlich 식이 잘 맞는다고 하여 본 연구와 유사한 연구결과를 나타냈다.

산성토양에 있어서 soil 1은 $60 \mathrm{mg} \mathrm{L}^{-1}$, soil 2는 $100 \mathrm{mg} \mathrm{L}^{-1}$, soil 3 는 $200 \mathrm{mg} \mathrm{L}^{-1}$ 의 농도 이상부터 인의 탈착반응이 일어 나기 시작하였다. 이것은 Adamson (1967)에 따르면 토양에 흡착된 인과 용액 중 이온간의 인력으로 생기는 흡착열의 변 이가 그 원인이라고 하였고, Kuo et al. (1974)에 의하면 고 농도에서 인의 포화도가 증가함에 따라 흡착열이 감소되면 서 규칙적 흡착으로부터 비 규칙적 흡착으로 옮겨가기 때문 이라고 하였다.

석회암 토양 (soil 4, 5, 6)에 있어서 반응용액 중 인의 평형 농도가 각각 50 100, 100 200, 400 600 mg L 일 때 등 온 흡착식의 기울기가 급격하게 변화하였다 (Fig. 1). 이러한 변화는 석회암 토양에 함유된 $\mathrm{CaCO}_{3}$ 와 인 사이에 침전 반응 이 일어났기 때문이라고 (Freeman and Rowell, 1981; Zhou and Li et al., 2001)하였다. 이와 유사하게 경작지인 시설재 배지 토양에서도 등온 흡착식의 기울기가 급격하게 변화하 였는데, 유효인산 $582 \mathrm{mg} \mathrm{kg}^{-1}$ 인 토양 (soil 7)은 인 평형 농 도가 $300 \sim 400 \mathrm{mg} \mathrm{P} \mathrm{L}^{-1}$ 에서, 유효인산 $1,218 \mathrm{mg} \mathrm{kg}^{-1}$ 인 토 양 (soil 8)은 인 평형 농도가 4,000 $5,000 \mathrm{mg} \mathrm{P} \mathrm{L}^{-1}$ 에서 기 울기가 급격하게 변화하였다 (Fig. 1). 이 토양은 $\mathrm{pH}$ 가 6.0 7.0에 있었고, 경작 시 투입한 농자재 (소석회, 석회고토, 가 축분 퇴비)의 영향으로 탄산칼슘 $(1.2 \sim 1.3 \%)$ 이 형성되어 침 전반응이 일어났을 것으로 추정한다. 유효인산 $2,148 \mathrm{mg}$ $\mathrm{kg}^{-1}$ 인 토양 (soil 9)의 인 흡착은 투입농도 $(1,000 \sim 5,000$ $\mathrm{mg} \mathrm{P} \mathrm{L}{ }^{-1}$ ) 내에서 지속적인 증가로 기울기의 변화를 살펴볼 
Table 2. Regression equation and detemination coefficient $\left(\mathbf{R}^{2}\right)$ using two adsorption equations for acidic, calcareous, and plastic film house soils.

\begin{tabular}{|c|c|c|c|c|c|c|c|}
\hline \multirow{2}{*}{ Soils } & \multirow{2}{*}{ Soil no. } & \multicolumn{3}{|c|}{ Langmuir } & \multicolumn{3}{|c|}{ Freundlich } \\
\hline & & Regression equation & $\mathrm{R}^{2}$ & RMSE. $^{\dagger}$ & Regression equation & $\mathrm{R}^{2}$ & RMSE. \\
\hline \multicolumn{8}{|c|}{ Non-cultivated soils } \\
\hline \multirow{3}{*}{$\begin{array}{l}\text { Acidic } \\
\text { soils }\end{array}$} & Soil 1 & $y=0.0046 x+0.0105$ & $0.998 * * *$ & 0.006 & $y=0.4189 x+3.8861$ & $0.825^{* *}$ & 1.051 \\
\hline & Soil 2 & $y=0.0013 x+0.0001$ & $0.994 * * *$ & 0.001 & $y=0.1972 x+5.8923$ & $0.944 * * *$ & 0.108 \\
\hline & Soil 3 & $y=0.0008 x+0.0065$ & $0.999 * * *$ & 0.008 & $y=0.3209 x+5.6824$ & $0.913 * * *$ & 0.157 \\
\hline \multirow{3}{*}{$\begin{array}{l}\text { calcareous } \\
\text { soils }\end{array}$} & Soil 4 & $y=0.0072 x+0.4545$ & $0.984 * * *$ & 0.039 & $y=0.3341 x+3.4874$ & $0.995 * * *$ & 0.059 \\
\hline & Soil 5 & $y=0.0015 x+0.0144$ & $0.982 * * *$ & 0.011 & $y=0.2773 x+5.1243$ & $0.996 * * *$ & 0.022 \\
\hline & Soil 6 & $y=0.0007 x+0.0243$ & $0.982 * * *$ & 0.018 & $y=0.2387 x+5.7616$ & $0.989 * * *$ & 0.051 \\
\hline \multicolumn{8}{|c|}{ Cultivated soils } \\
\hline \multirow{3}{*}{$\begin{array}{c}\text { Plastic } \\
\text { film house } \\
\text { soils }\end{array}$} & Soil 7 & $y=0.0009 x+0.129$ & $0.858 * * *$ & 0.009 & $y=0.573 x+3.373$ & $0.979 * * *$ & 0.105 \\
\hline & Soil 8 & $y=0.0002 x+0.354$ & $0.877 * * *$ & 0.127 & $y=0.195 x+6.3028$ & $0.872 * * *$ & 0.087 \\
\hline & Soil 9 & $y=-0.004 x+14.519$ & 0.576 & 5.077 & $y=3.285 x-17.482$ & $0.869^{* *}$ & 0.822 \\
\hline
\end{tabular}

ns : Non significance

* : level of significance $\mathrm{p}<0.05$

$* *$ : level of significance $\mathrm{p}<0.01$

$* * *$ : level of significance $\mathrm{p}<0.001$

$\dagger$ : root mean square error.
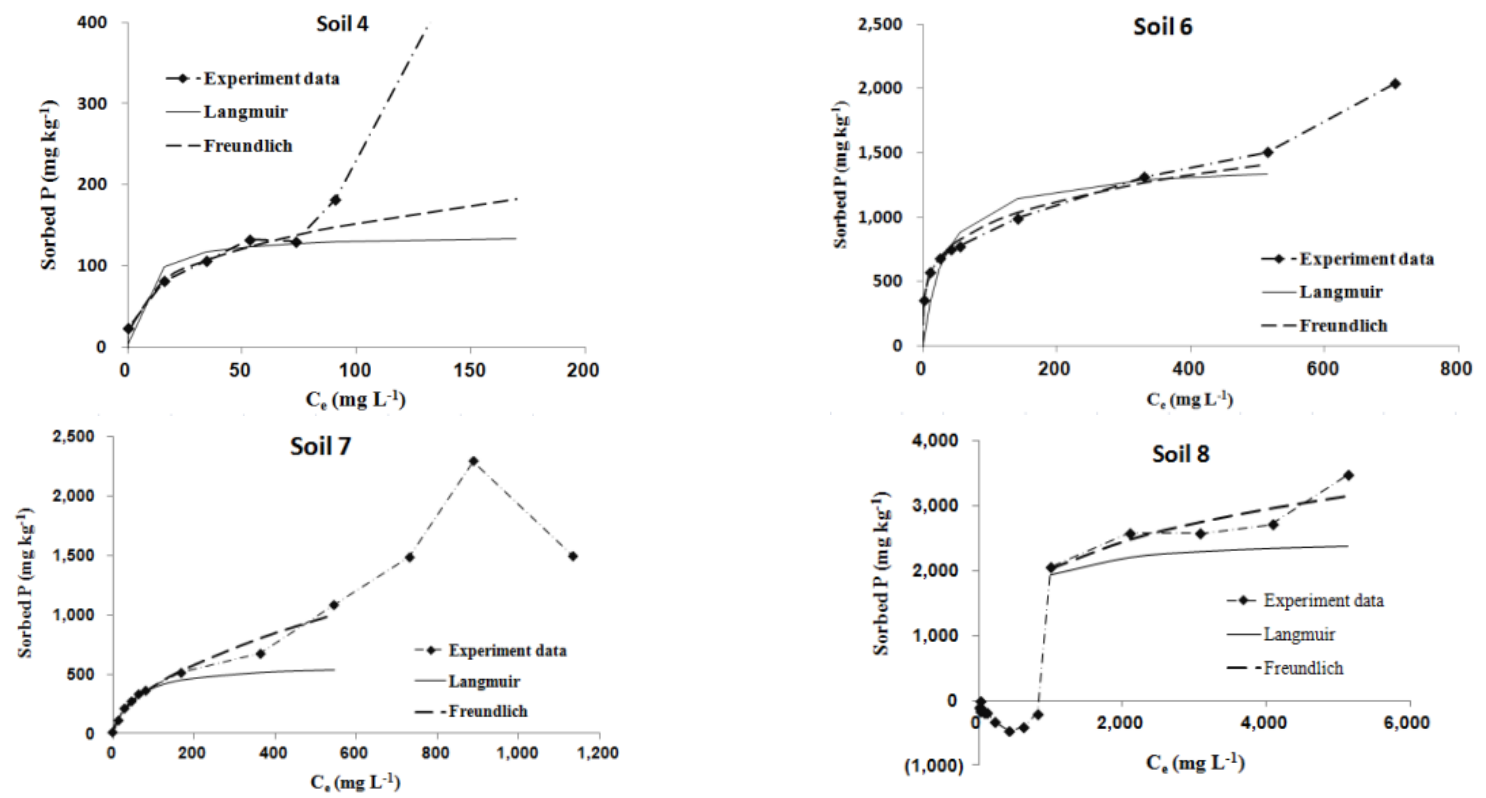

Fig. 1. Comparison of observed and predicted adsorptions using Langmuir and Freundlich isotherm equations. Soil 4 and Soil 6 are calcareous soils and Soil7 and Soil 8 are plastic film house soils.

수 없었다.

이로부터 시설재배지 토양에 $\mathrm{CaCO}_{3}$ 와 인 사이에 침전반응 이 일어나 불용화 과정이 진행되고 있었고, 침전형태의 인은 작물에 유효도가 낮기 때문에 침전반응이 일어나지 않도록 토양에서의 인 성분을 관리하는 것이 매우 중요하다고 생각 된다.

침전반응이 일어나지 않은 범위로 인을 관리하기 위해 토 양의 인 최대 흡착량을 Langmuir 식으로 구하였다. 산성토
양에서 점토함량이 $11 \%, 23 \%, 37 \%$ 로 증가할 때 각각 217 , $909,1,250 \mathrm{mg} \mathrm{kg}^{-1}$ 으로 증가하였고, 석회암 토양에서 점토 함량이 $4 \%, 22 \%, 46 \%$ 로 증가할 때 각각 $139,769,1,429 \mathrm{mg}$ $\mathrm{kg}^{-1}$ 으로 증가하였다 (Table 3). 이것은 토양 중 점토 함량이 많아지면 인이 흡착할 수 있는 표면적이 많아지기 때문이다 (Yan et al., 2013). 점토함량 $(22 \sim 23 \%)$ 이 유사한 $\mathrm{pH}$ 가 다른 산성 토양과 석회암 토양의 인 최대흡착량은 각각 909,769 $\mathrm{mg} \mathrm{kg}^{-1}$ 으로 산성토양이 석회암 토양보다 높았는데, 이것은 
Table 3. Langmuir and Freundlich isotherm adsorption parameters of acidic and, calcareous, and plastic film house soils.

\begin{tabular}{|c|c|c|c|c|c|}
\hline \multirow{3}{*}{ Soils } & \multirow{3}{*}{ Soil no. } & \multicolumn{2}{|c|}{ Langmuir } & \multicolumn{2}{|c|}{ Freundlich } \\
\hline & & $S_{\max }$ & $\mathrm{k}$ & $\mathrm{K}_{\mathrm{d}}$ & $\mathrm{n}$ \\
\hline & & $\mathrm{mg} \mathrm{kg}^{-1}$ & $\mathrm{~L} \mathrm{mg}^{-1}$ & $\mathrm{~L} \mathrm{~kg}^{-1}$ & \\
\hline \multicolumn{6}{|c|}{ Non-cultivated soils } \\
\hline \multirow{3}{*}{$\begin{array}{l}\text { Acidic } \\
\text { soils }\end{array}$} & Soil 1 & 217 & 0.438 & 49 & 0.419 \\
\hline & Soil 2 & 909 & 0.262 & 304 & 0.289 \\
\hline & Soil 3 & 1,250 & 0.123 & 294 & 0.321 \\
\hline \multirow{3}{*}{$\begin{array}{l}\text { calcareous } \\
\text { soils }\end{array}$} & Soil 4 & 139 & 0.159 & 33 & 0.334 \\
\hline & Soil 5 & 769 & 0.048 & 168 & 0.277 \\
\hline & Soil 6 & 1,429 & 0.029 & 318 & 0.239 \\
\hline \multicolumn{6}{|c|}{ Cultivated soils } \\
\hline \multirow{3}{*}{$\begin{array}{l}\text { Plastic film } \\
\text { house soils }\end{array}$} & Soil 7 & 714 & 0.014 & 36 & 0.518 \\
\hline & Soil 8 & - & - & - & - \\
\hline & Soil 9 & - & - & - & - \\
\hline
\end{tabular}

$\mathrm{S}_{\max }$ is $\mathrm{P}$ maximum sorption, $\mathrm{k}$ : a constant to the bonding energy, $\mathrm{K}_{\mathrm{d}}$ and $\mathrm{n}$ are constants for a given adsorbate and adsorbent at a particular temperature.

석회암 토양에서 동일한 흡착 위치를 두고 $\mathrm{OH}^{-}$와 인이 경쟁 하기 때문이다 (Parfitt, 1977; Rajan et al., 1974).

유효인산 함량이 $582 \mathrm{mg} \mathrm{P} \mathrm{kg}^{-1}$ 인 시설재배 토양의 인 최 대 흡착량은 $714 \mathrm{mg} \mathrm{P} \mathrm{kg}$ 이었고, 유효인산 함량이 1,218 $\mathrm{mg} \mathrm{kg}^{-1}, 2,148 \mathrm{mg} \mathrm{kg}^{-1}$ 인 토양의 인 최대 흡착량은 구할 수 없었다. 이것은 가축분퇴비와 석회고토와 같은 농자재의 투 입으로 $\mathrm{CaCO}_{3}$ 와 인이 결합하여 새로운 침전물을 지속적으로 발생한다고 추정한다. 이러한 농자재의 종류와 투입량에 따른 토 양의 인 흡착과 침전반응의 체계적인 해석은 추후 연구가 더 필요 한 분야라고 생각한다. 점토 함량이 증가함에 따라Freundlich 식 의 분배계수 $\left(\mathrm{K}_{\mathrm{d}}\right)$ 값은 커지는 경향이었고, 토양에 대한 인 흡 착력을 나타내는 $\mathrm{n}$ 값은 작아졌다. $\mathrm{n}$ 값은 작을수록 토양의 인 흡착력이 커진다고 볼 수 있다.

토양의 인 최대흡착량은 흡착반응에서 침전반응으로 전환 되는 임계 농도로 평가할 수 있고, 이 농도 이하로 농경지의 인 을 관리하는 것이 인산집적을 예방하는 방법이라 생각한다.

\section{One-point 등온흡착을 이용한 인 최대 흡착량 추정} Langmuir 식으로부터 인의 최대 흡착량을 구할 경우 토양과 혼합하는 인 용액의 수가 많고 분석이 복잡하며 시간이 많이 걸리는 단점이 있다. 이러한 문제를 해결하는 방법으로 인 최 대흡착량을 추정할 때 One-point 등온흡착 방법이 사용될 수 있다. 이 실험에서 토양에 투입하는 인 용액농도를 각각 $20,60,100 \mathrm{mg} \mathrm{L} \mathrm{L}^{-1}$ 일 때 토양의 인 흡착량과 이 토양의 Langmuir식으로 추정한 인 최대 흡착량과의 관계를 살펴본 결과, 유의성이 높은 $\left(\mathrm{R}^{2}=0.807 \sim 0.844\right)$ 직선관계가 성립 하였다 (Fig. 2). Zhou and Li (2001)에 따르면, one-point 흡착 실험에서 초기에 투입하는 인 용액농도가 $400 \mathrm{mg} \mathrm{L}^{-1}$ 일
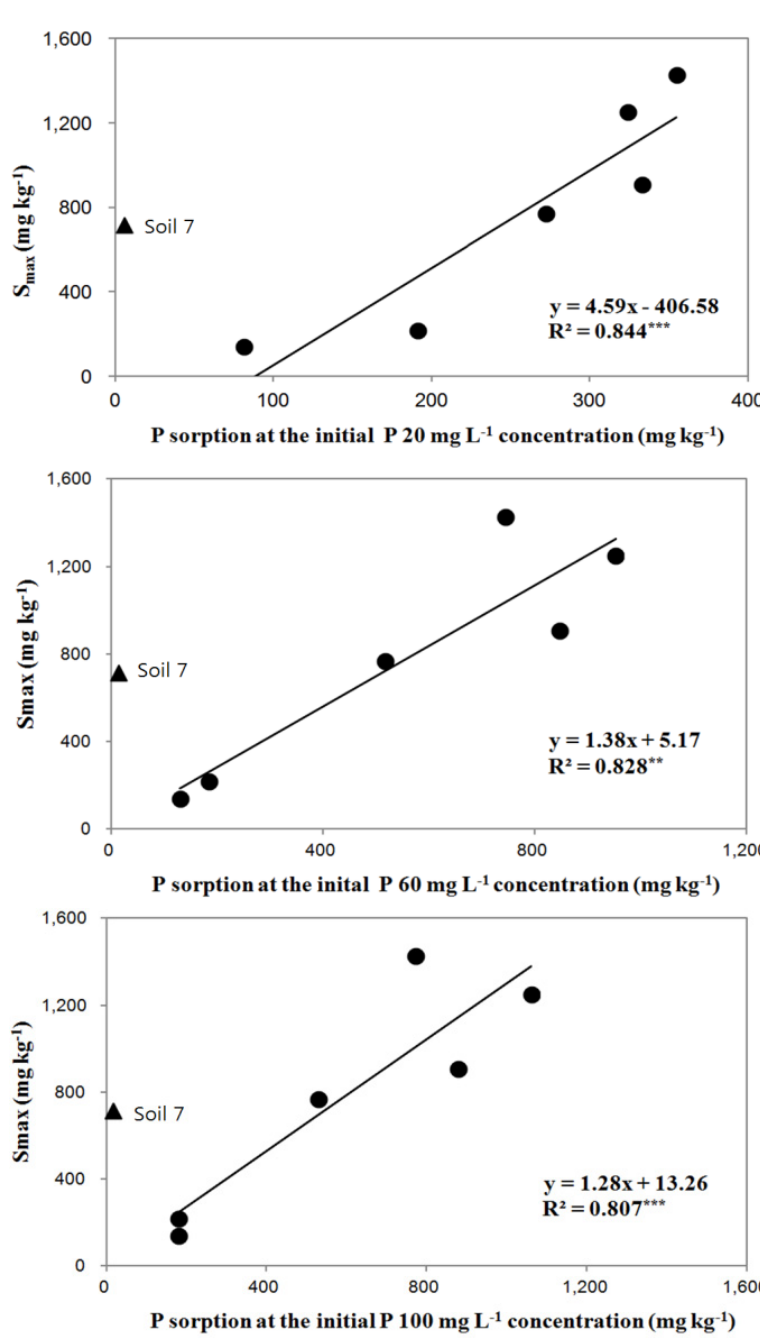

Fig. 2. Relationships in soils of $P$ sorption values of the Langmuir $S_{\max }$ to those of one-point sorption at the initial $P$ 20, 60, $100 \mathrm{mg} \mathrm{L}^{-1}$, respectively. $\mathrm{ns}$ : Non significance, *** : level of significance $\mathbf{p}<0.001$. 
때 토양의 인 흡착량과 Langmuir식으로 구한 인 최대 흡착량 사이에 직선적으로 유의성이 높은 관계에 있다고 하여 one-point 등온흡착 방법으로 최대흡착량을 추정할 수 있다 고 하였다. 그러나, 본 연구에서 초기에 투입하는 인 용액농 도를 $400 \mathrm{mg} \mathrm{L}^{-1}$ 으로 할 경우 점토함량이 낮은 토양에서 인 탈착이 일어나기 때문에 국내 토양에서 one-point 등온 흡착 으로 인 최대흡착량을 추정할 경우 투입하는 인의 농도는 20 $\mathrm{mg} \mathrm{L}^{-1}$ 가 적당하리라 판단된다. 그러나, 경작지 토양인 시설 재배토양 (Soil 7)에 각각 20,60, $100 \mathrm{mg} \mathrm{L}^{-1}$ 을 넣고 구한 one-point 흡착량은 Langmuir식으로 구한 인 최대 흡착량 과는 잘 맞지 않아 인 최대 흡착량을 추정할 수 없었다.

\section{Conclusion}

토양특성별 인 흡착기작과 최대 흡착량을 평가하고자 $\mathrm{pH}$, 점토함량이 다른 미경작지 토양과 유효인산 함량이 높은 시설 재배지의 경작지 토양을 분석하였다. 인 흡착 기작은 미경작 지인 산성토양에서 Langmuir 식에 의해, 미경작지인 석회암 토양과 경작지 시설재배 토양은 Freundlich 식에 의해 잘 설명 되었다. 특히 석회암 토양과 시설재배 토양의 흡착식에서 기 울기가 급격하게 변화하는 시점은 인 최대흡착량 이후에 나타 나는 침전반응이므로, 농경지 내에서 침전물이 형성되지 않도 록 인의 최대흡착량 이하로 관리하는 것이 중요하다.

토양특성별 인 최대 흡착량은 산성토양 (4.4)에서 점토함 량이 $11,23,37 \%$ 일 때 각각 $217,909,1,250 \mathrm{mg} \mathrm{P} \mathrm{kg}^{-1}$ 로 증 가하였고, 석회암 토양 $(\mathrm{pH}$ 8.0 8.2)에서 점토함량이 4 , $22,46 \%$ 일 때 $139,769,1,429 \mathrm{mg} \mathrm{P} \mathrm{kg}^{-1}$ 으로 증가하였으며, 시설재배 토양에서 인산함량이 높은 토양에서 구할 수 없었 다. 그리고 미경작지의 산성과 석회암 토양의 Langmuir 인 최대흡착량은 one-point 등온흡착 방법으로 간단하게 추정 할 수 있었고, 투입하는 인의 적정 농도는 $20 \mathrm{mg} \mathrm{L}^{-1}$ 으로 나 타났다.

\section{References}

Adamson, A.W. 1967. Physical chemistry of sufraces. Interscience Publishers, Inc., New York. 650-654.

Fox, R.L. and E.J. Kamprath. 1970. Phosphate sorption isotherms for evaluating the phosphate requirements of soils. Soil Sci. Soc. Am. Proc. 34:902-907.

Freeman, J.S. and D.L. Rowell. 1981. The adsorption and precipitation of phosphate onto calcite. J. Soil Sci. 32:75-84.
Freundlich, H. 1926. Colloid and capillary chemistry. Methuen, London.

Jung, W.K. and Y.H. Kim. 2006. Soil organic carbon determination for calcareous oils. Korean J. Soil Sci. Fert. 39(6):396-402.

Kuo, S. and E.G. Loste. 1974. Kinetics of phosphate adsorption by calcium carbonate and Ca kaolinite. Soil Sci. Soc. Amer. Proc. 36:725-729.

Langmuir, I. 1918. The adsorption of gases on plane surfaces of glass, mica and platinum. J. Am. Chem. Soc. 40:1361-1403.

NIAST. 2000. Methods of soil analysis. NIAST, RDA, Suwon, Korea.

NIAST. 2006. Fertilizer Recommendation for crops (revision). National Institute of Agricultural Science and Technology, RDA, Suwon, Korea.

Parfitt, R.L. 1989. Phosphate reactions with natural allophane, ferrihydrite and goethite. J. Soil Sci. 40:359-369.

Rajan, S.S.S. and R.L. Fox. 1974. Phosphate adsorption by soils. II. Reactions in tropical acid soils. Soil Sci. Sci. Soc. Am. J. 39:846-851.

RDA. 2013. Monitoring project on agri-environment quality in Korea. Rural Development Administration, Suwon, Korea.

Ryan, J., D. Curtin, and M.A. Cheema. 1985. Significance of iron oxides and calcium carbonate particle size in phosphate sorption by calcareous soils. Soil Sci. Soc. Am. J. 49:74-76.

Ryu, I.S. 1975. Comparison between phosphorus adsorption coefficient and Langmuir adsorption maximum. J. Korean Soc. Sci. Fert. 8(1):1 17.

Sanyal, S.K., S.K. De Datta, and P.Y. Chan. 1993. Phosphate sorption-desorption behavior of some acidic soils of south and southeast Asia. Soil Sci. Soc. Am. J. 57:937-945.

Solis, P. and J. Torrent. 1989. Phosphate sorption by calcareous vertisols and inceptisols of Spain soils. Soil Sci. Sci. Soc. Am. J. 53:456-459.

Sparks, D.L. 2003. Environmental Soil Chemistry, third ed., Academic press, New York, USA, 2003.

Yan, X., D. Wang, H. Zhang, G. Zhang, and Z. Wei. 2013. Organic amendments affect phosphorus sorption characteristics in a paddy soil. Agriculture, Ecosystems and Environment, 175: 47-53.

Yun, H.B., Y.J. Lee, J.K. Sung, M.S. Kim, S.M. Lee, S.C. Kim, and D.B. Lee. 2013. Estimation of potential NPK input from livestock wastes since 1990. Proceeding of Korean Soc. of Soil Sci. Fert. pp. 156-156.

Zhou, M. and Y. Li. 2001. Phosphorus-sorption characteristics of calcareous soils and limestone from southern Everglades and adjacent farmlands, Soil Sci. Soc. Am. J. 65:1404-1412. 